\title{
06
}

\section{EFFECT OF CHANGING VEGETATION COVERAGE AND TEMPERATURE ON THE MONSOON PATTERN OF INDIAN SUNDARBAN REGION}

\author{
Papia Guha ${ }^{*}$, Pritam Aitch ${ }^{2}$ and Gupinath Bhandari ${ }^{3}$ \\ ${ }^{1}$ Research Scholar, ${ }^{2,3}$ Associate Professor \\ Department of Civil Engineering, Jadavpur University, Kolkata, West Bengal, India, \\ Email: guhapapia76@gmail.com, pritamaitch@gmail.com, g.bhandari.ju@gmail.com
}

\begin{abstract}
Sundarban, the grand symphony of nature at the confluence of Bay of Bengal covers an area of about 25,500 sq. km. The Present study is over Indian Sundarban Delta (ISD) covering an area of about 9,630 sq. $\mathrm{km}$. ISD is known for its immense biological diversity and its importance for protecting West Bengal from natural hazards and changing climatic conditions. But the constant changes in atmospheric and ecological structure have disrupted the region by changing the pattern of precipitation. Henceforth, the study is made to depict the reason behind such changes. Vegetation cover change is being detected by analysing images of Landsat USGS using Remote Sensing which was further used to generate a thematic map using GIS. Secondary data on Rainfall and Temperature changes were analysed using Excel. Analysis depicted that decreasing vegetation coverage and the increasing temperature is having a harming negative impact on the changing monsoon. Such will also help to depict the socio-economic condition of the region.
\end{abstract}

Key words: Sundarban Delta, Rainfall Pattern, Temperature Change, Vegetation Coverage.

\section{Introduction}

The awe-inspiring adobe of nature "Sundarban" is covering an area of $25,500 \mathrm{sq}$. km spanning across both India and Bangladesh. 9,630 sq. km out of this is designated as Indian Sundarban Delta (ISD). Situated at the confluence of Bay of Bengal it is a part of the largest GangaBrahmaputra Delta. Delineated between $21^{\circ} 32^{\prime}-22^{\circ} 40^{\prime} \mathrm{N}$ and $88^{\circ} 05^{\prime}-89^{\circ} 00^{\prime} \mathrm{E}$ Indian Sundarban comprises with the most diversified mangrove cover along with the pride "Royal Bengal Tiger". Sundarban has been designated as "World Heritage Site" by "UNESCO" in the year 1997. This huge intertidal area consists of islands that are about 102 in number with 42 lakh inhabitants (Das 2011). Hence, it maintains harmony between nature and human life to summarize a proper ecological balance. Its mangrove trees to water resources all provide an occupational option for the inhabitants (Guha et al 2017). Apart from all these the region is on the verge of climatic disparity. The Climate of this region is always dynamic. But with the due course of time as global warming jailed nature, the climate of the region started behaving in a most unhealthy way. Moreover, the mangrove or the Sundari plants, for which the region is named, are also loosing as years are passing. Hence, both these major factors i.e. vegetation coverage and increasing temperature character is impacting the climate of the region. The major impact is on the monsoon pattern as noticed by the present work. Monsoon, as suggested is between JuneSeptember (Mondal 2004). It has also been reported that August is the major monsoon rainfall contributing month (Guhathakurata, Rajevvan 2006). Researchers also claimed that 85 percent of monsoon rain occurs during advancing monsoon tenure (Gupta n.d). Changing in monsoon patterns is thus a global concern. Moreover, in ISD its disparity is impacting the ecological to economic balance. To find out the cause - the present work mainly relied on the temperature and vegetation coverage impact on monsoon pattern. Present research work is giving an insight into the blooming threat in terms of changing monsoon patterns.

\section{Methodology}

The Present research study is being carried out in the Indian Sundarban Delta (ISD) as shown in Figure 1. Source: A (West Bengal - Simple English Wikipedia, the free encyclopaedia.), B (West Bengal State. Onefevenine.com), C - Present Research work concluded from Arc GIS Software. The Importance of the study is directly dedicated to the inhabitants of the region and the entire city of Kolkata. Working for the same is being busted under the following phases: 
A. Vegetation coverage Analysis is being interpreted by using Cloud-free images of Landsat 45 TM (Thematic Mapper) of years 2005, 2007, 2008, 2009, 2011 and 2012

B. Temperature Change Analysis.

C. Monsoon Pattern change identification.

D. Impact of Vegetation Coverage and Changing Temperature on Monsoon Pattern.

Figure 01: Study Area: Indian Sundarban Delta (ISD)

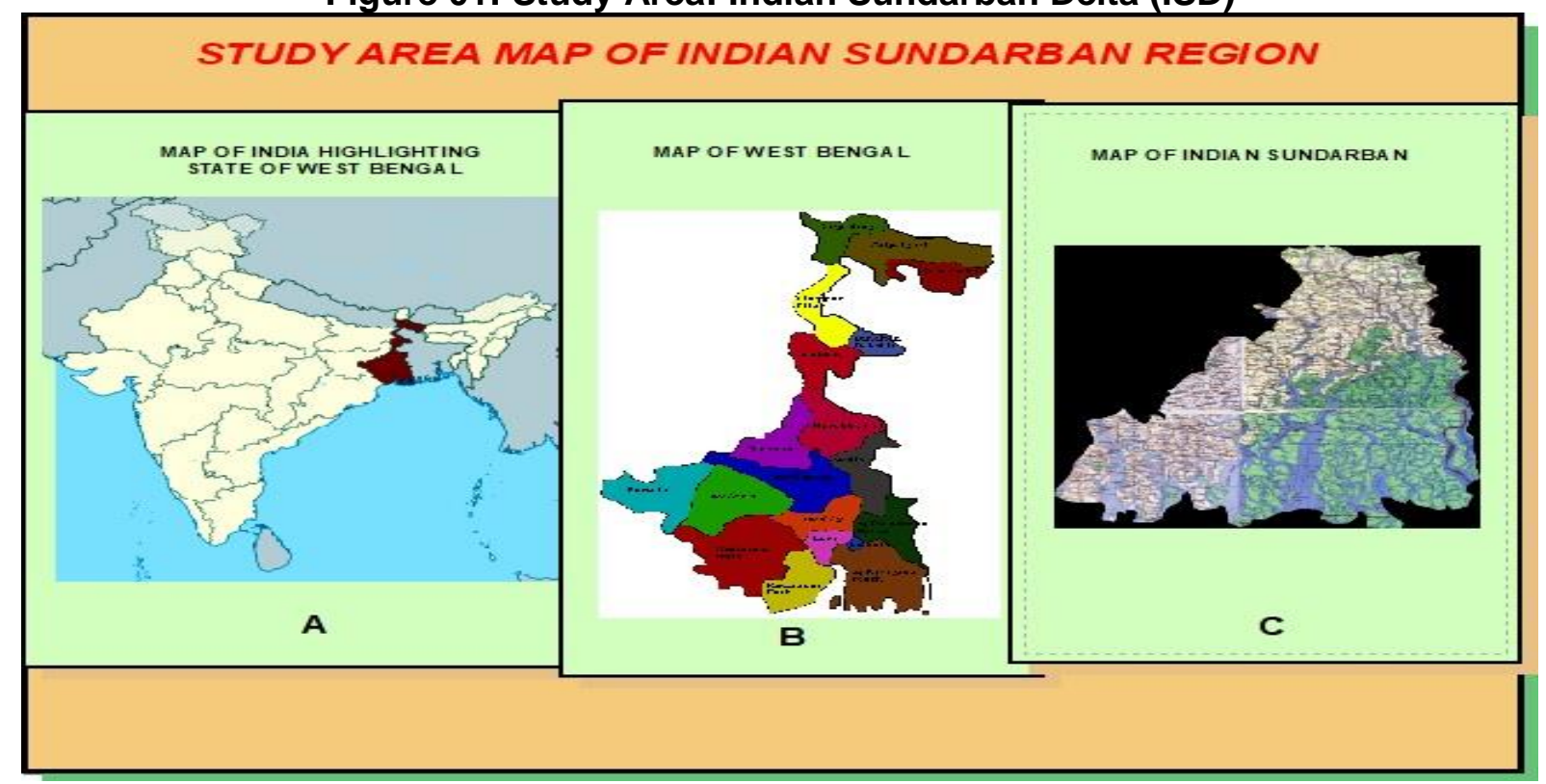

Vegetation Coverage Analysis Using Satellite Technology

For the present analysis, LANDSAT 4-5 TM cloud-free images of Path - 138, Rows - 44 and 45 for 2005, 2007, 2008, 2009, 2011 and 2012 have been studied. The said images have been achieved from EARTH EXPLORER -LANDSAT USGS (USGS, n.d.). Coverage Count has been determined by NORMALIZED DIFFERENCE VEGETATION INDEX (NDVI) procedure. Vegetation percentage is being at present times determined by vegetation indices like NDVI, by utilizing e spectral reflectance of various vegetation covers via satellite data (Guha et al., 2019). The process of acquiring vegetation information over a vast area is also cost-effective (Das and Singh 2013). Moreover, researchers have acclaimed NDVI to be the most widely used vegetation cover identification (Manna et.al 2012). Before such analysis the images are channelled through "pre-processing" steps via ERDAS IMAGINE software:

- Firstly, "Layer Stacking " coupled all the layers of both the rows of 44 and 45 respectively.

- Such is followed by the "Mosaiking" of layers-tacked images of rows 44 and 45 respectively.

- Area of Interest or AOI has been then "subsisted" from the whole mosaicked image.

- Subsisting, finally lead to the formation of the Indian Sundarban Delta.

\section{Analysis of Temperature Change}

Temperature change analysis is being done by calculating the annual average temperature of 2005-2012 with the acquired secondary data from Government of West Bengal's Department of Agriculture (Directorate of Agriculture 2017) in Excel Statistics.

\section{Monsoon Pattern Change Analysis}

For monsoon, the pattern changes the present study conducted - identification of trend of the number of rainy days as well as of average rainfall of monsoon times from 2005-2012. Research already suggested that the pattern of the monsoon of Sundarban is changing (Pitchaikani et.al 2015). Secondary data for rainfall has been taken from Government of West Bengal's Department of Agriculture (Directorate of Agriculture. 2017).

\section{Impact of Vegetation Coverage and Temperature Change on Monsoon Pattern Analysis}

The Impact of both Vegetation and temperature change has been glorified via a scatter graph with further incorporation of the Trend statistics analysis.

\section{RESULTS AND DISCUSSIONS}

From the NDVI, the vegetation coverage area in Sq. Km has been identified. In Figures. 2, 3 and 4, the Thematic Maps are showing the NDVI classification respectively. 


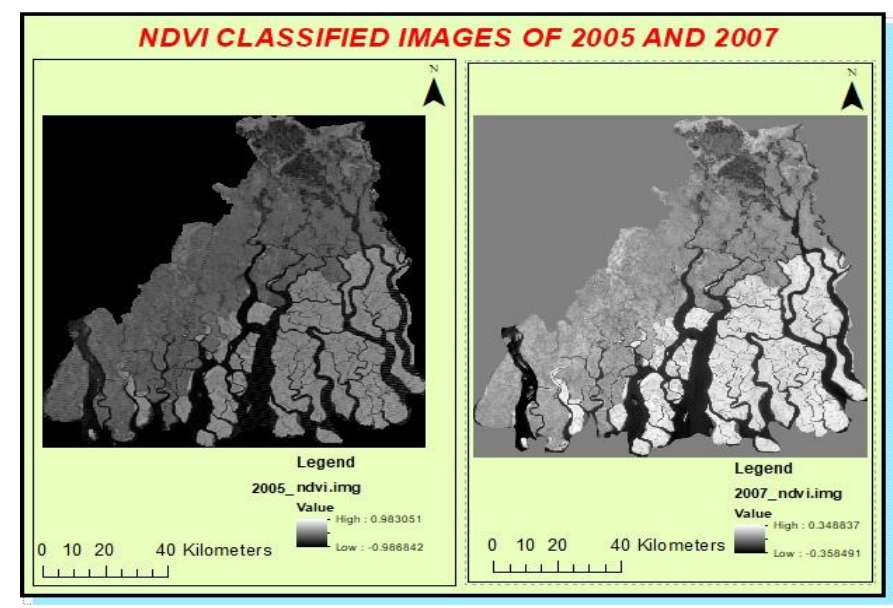

Figure 02: NDVI Classified Images of 2005 and 2007

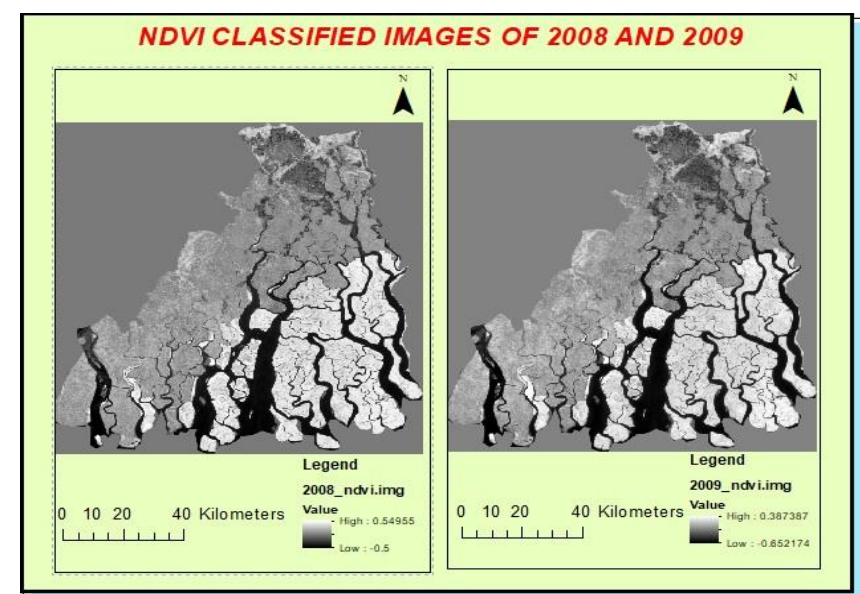

Figure 03: NDVI Classified Images of 2008 and 2009

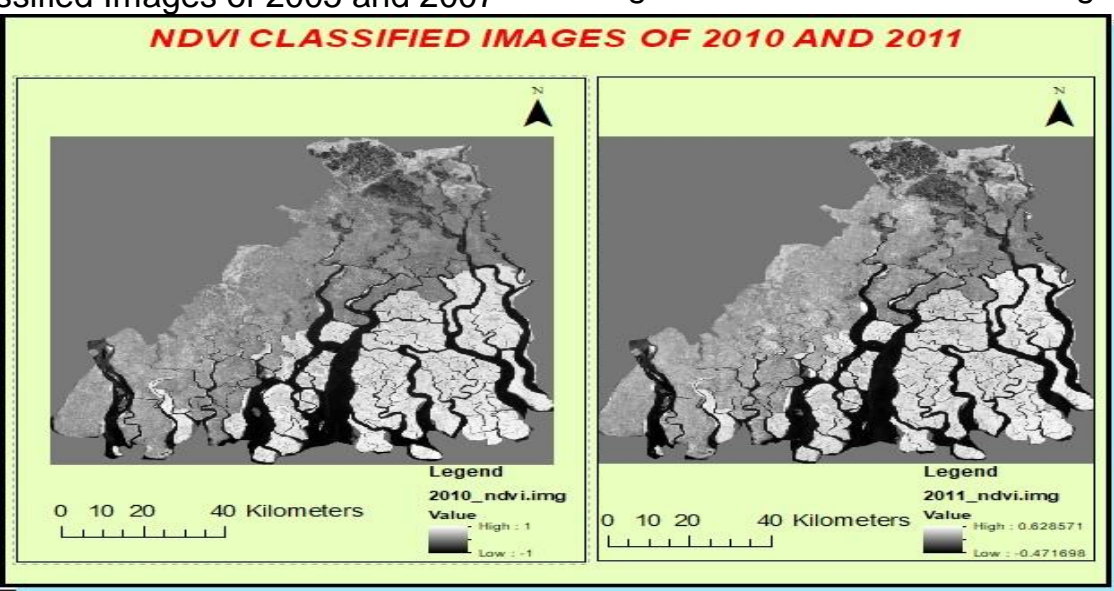

Figure 04: NDVI Classified Images of 2010 and 2011

Graphically, a linearly decreasing trend of vegetation coverage with time is represented in Figure 5. This, in turn, is initiating to indicate that disparity in ecological balance is blooming an alarming threat. Similarly, increasing average Temperature via scattering graph (Figure 6) and the changing monsoon patterns: Rainy days (Figure 7) and Monsoon Average count (Figure 8) in total is indicating to the onset of the radical climatic changes of ISD. Amidst such alarming environmental conditions, added caution ringed when the successive statistical and graphical analysis indicated that decreasing vegetation decreases the monsoon rainfall (Figure 9) as well as the rainy days (Figure 10). Researchers also said that various land processes including vegetation at different temporal and spatial scale influence the climatic system (Dutta et.al 2009). Alongside this, increasing temperature threat poised that temperature negatively (decreases) impacts both the Rainfall count (Figure 11) and Rainy day count (Figure 12).

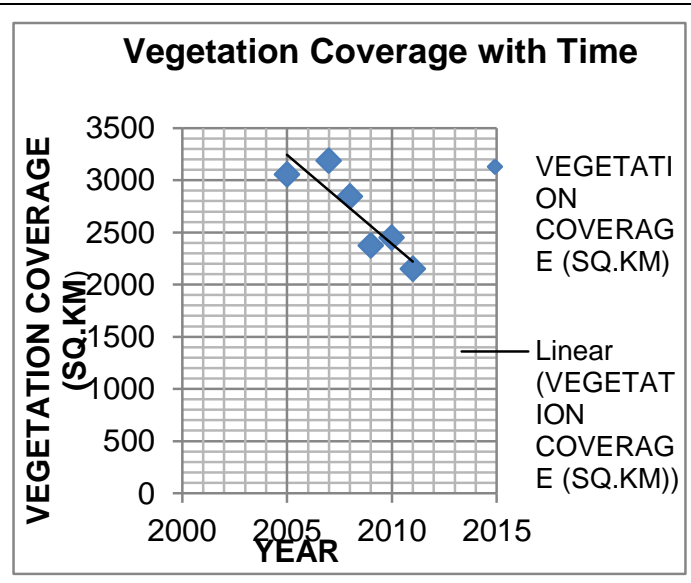

Figure 05: Decreasing Vegetation Trend with time.

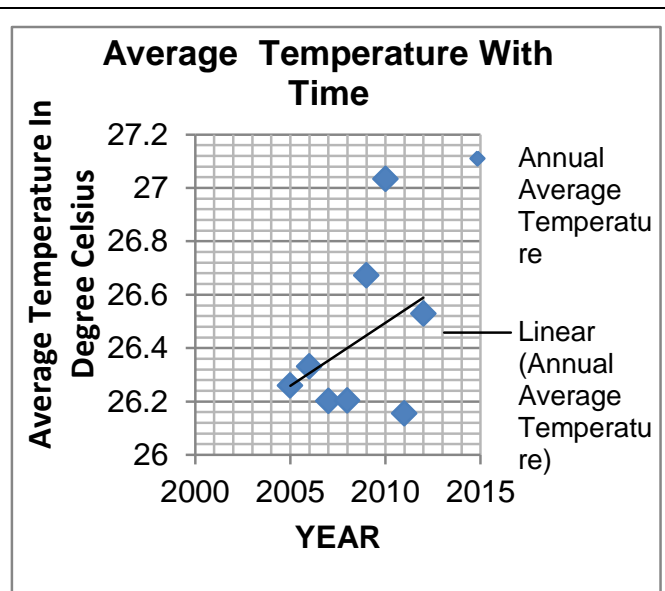

Figure 06: Increasing Temperature Trend with time. 


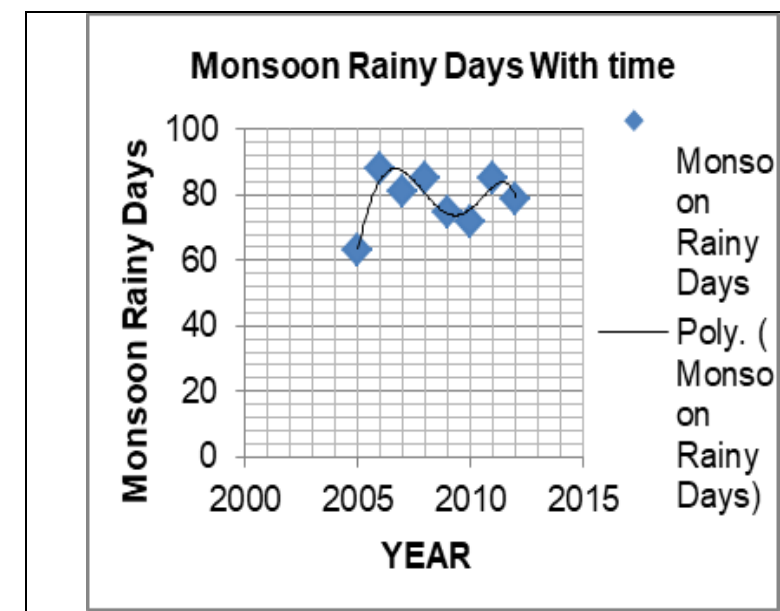

Figure 07: Monsoon Rainy Days radical changing pattern with decreasing mode

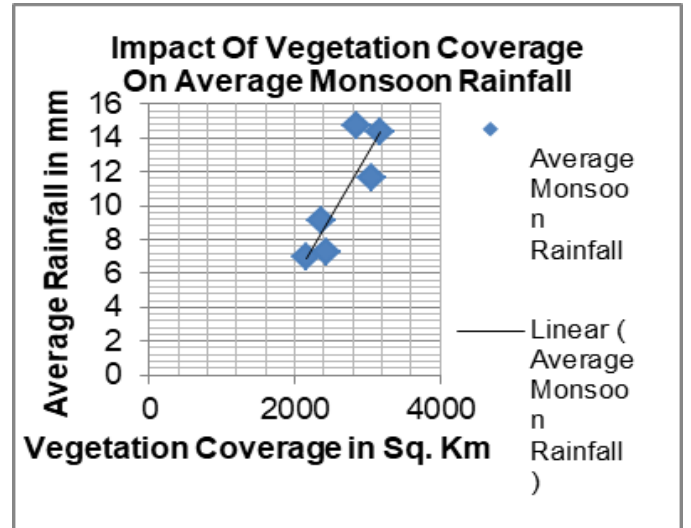

Figure 9: Vegetation Area Impact on Monsoon Average Count.

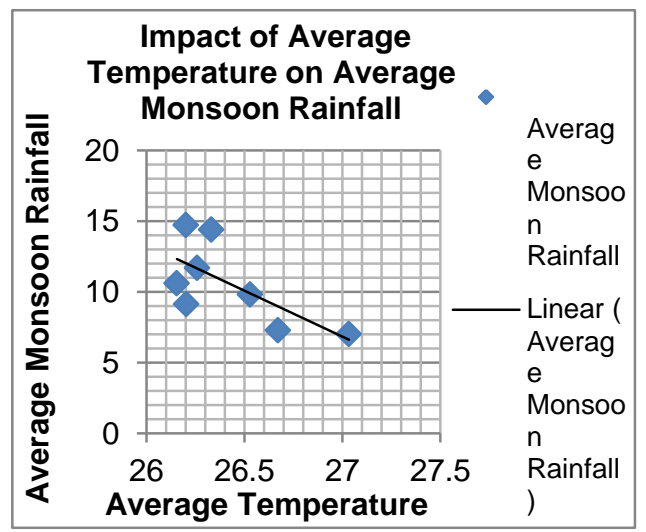

Figure 11: Average Temperature Impact on Monsoon Rainfall Count.

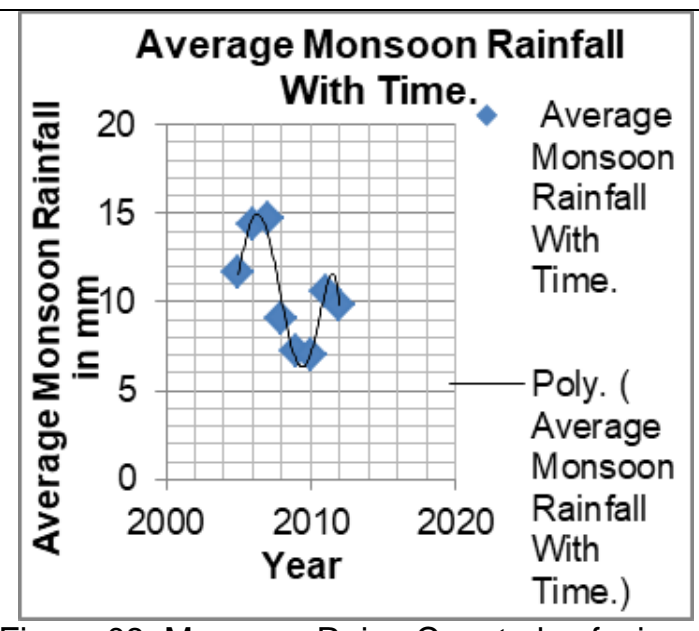

Figure 08: Monsoon Rainy Count also facing a decreasing end.

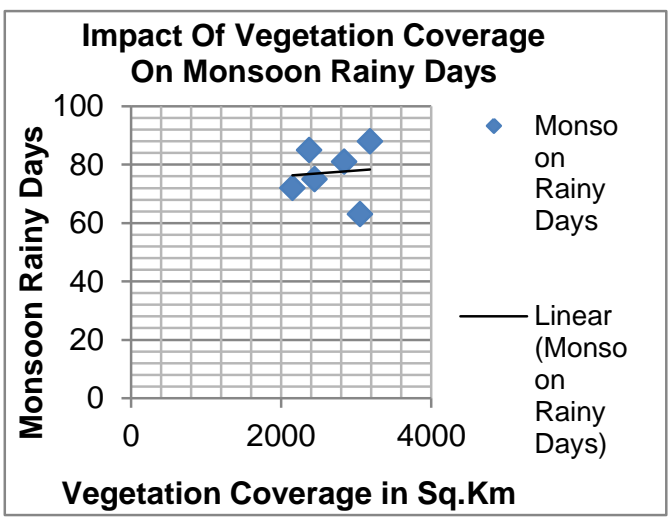

Figure 10: Vegetation Area Impact on Monsoon Rainy Days.

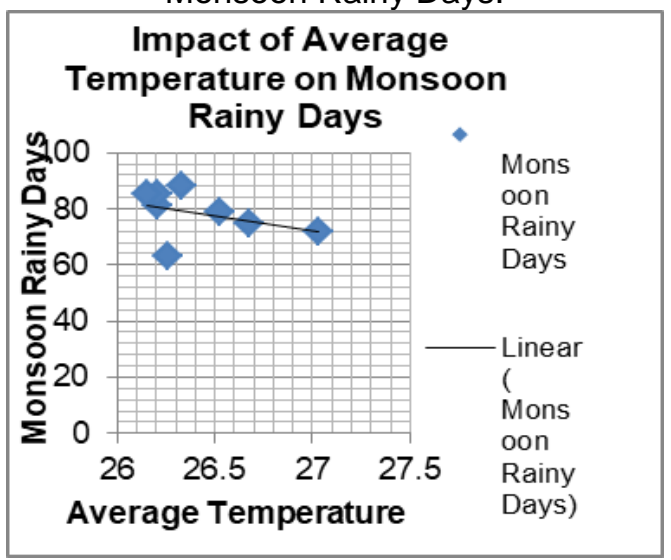

Figure 12: Average Temperature Impact on Monsoon Rainy days.

\section{Conclusion}

Present research ranged a long alarm for the India Sundarban Delta with the prefix to the entire state of West Bengal, as, the state looks forward to protection under natural calamities to ISD. Outcomes oozed that in this era of global warming ISD is also on the same track of threat with increasing average temperature along time. We need to mention here that the daily surface temperature of India has increased by a maximum of $1-1.5^{\circ} \mathrm{C}$ (Halder et.al 2016). Indian Sundarban Delta is meant for its biodiversity and ecological balance which nurtures a healthy count for the entire state. But with the gradual fall of Vegetation such balance is being under question. Since Remote Sensing most prominently determines the coastal vegetation cover (Nayak and Bahuguna 2001), hence, here also the NDVI process has been undertaken. An added concern is the conditioning of Monsoon pattern with pace in this region. Again, Indian summer monsoon i.e., from June to September varies largely (Rasul and Chaudhry n.d). Research penned here that decreasing vegetation and increasing temperatures are the major causes behind the rainfall count and rainy day count diminishing. If in this way the rainfall 
decreases then the inflow of fresh water will also be decreased. Hence, an abrupt increase of salinity will cause the extinction of many mangrove species (which is the major and key vegetation of ISD). Extinction or death or natural uprooting of mangrove species will make the ISD more naked to natural hazards-will hamper the food cycle of the entire eastern zone fish community - will directly impact the economy of dependent inhabitants and majorly, will in the total impact the climatic as well as an ecological condition leading to more fierce environmental scenario . In support of this, 2010 WWF (Danda 2010) report can be referenced where it is mentioned that the changing monsoon pattern is leading to social imbalance. Hence, an immediate sustainable proper management plan is a much-needed factor for saving the most fragile ecosystem of the Indian Sundarban Delta.

\section{References}

1. Danda, A. (2010) Sundarbans: Future Imperfect. Climate Adaptation Report. WWF. India.

2. Das, K. G. (2006) A Book on Sunderbans environment and ecosystem. Kolkata. Sarat Book House Publications.

3. Das, S. and Singh, T.P. (2013) Mapping vegetation and forest types using Landsat TM in the western ghat region of Maharashtra, India. International Journal of Computer Applications, 76 (1), 33-37.

4. Directorate of Agriculture. (2017) Monthly Meteorological Report. Agri-Met Section. Baruipur Station. Government of West Bengal.

5. Dutta, K, S., et.al. (2009) Impact of vegetation on the simulation of seasonal monsoon rainfall over the Indian subcontinent using a regional model. Journal of Earth System Science. 118(5), 413-440.

6. Guha, P., Aitch, P. \& Bhandari, G. (2017) Assessing the Landmass shift at Indian Sundarban Region and its impact using geospatial technology. Indian Cartographer Geoinformatics for Carto-Diversity and its management. 37, 277-282.

7. Guha, P., Aitch, P. \& Bhandari, G. (2019) Effect of changing vegetation coverage and meteorological parameters on the hazard characteristics of the Indian Sundarban Region and its impact there on.

8. Guhathakurata, P. \& Rajevvan, M. (2006) Trends in the rainfall pattern over India. NCC Research Report. India Meteorological Department. Pune.

9. Gupta, T. (2019) Characteristics of Monsoon Rainfall in India. Available from: http://www.preservearticles.com [Accessed 19th September 2019]

10. Halder, S., Saha, S. K., Dirmeyer, P. A., Chase, T. N. \& Goswami, B. N. (2016) Investigating the impact of land-use land-cover change on Indian summer monsoon daily rainfall and temperature during 1951-2005 using a regional climate model. Journal of Hydrology and Earth System Sciences. 20, 1765-1784.

11. Ibrahim, M. \& Al-Mashagbah, A. (2016) Change Detection of Vegetation Cover Using Remote Sensing data as a case study: Ajloun area. Civil and Environmental Research, $8(5)$.

12. Jagan Eedula. (2011) West Bengal State. Available from: http://www.onefivenine.com/india/villag/state/West-Bengal [Accessed 12th August 2019]

13. Manna, S., Mondal, P. P., Mukhopadhayay, A., Akhand, A., Hazra, S., \& Mitra, D. (2013) Vegetation cover change analysis from multi-temporal satellite data in Jharkhali Island, Sundarbans, India. Indian Journal of Geo-Marine Sciences, 42(3), 331-342.

14. Mondal, K. A. (2004). A Book on The Sundarbans of India - A developmental analysis. New Delhi, Indus Publishing Company.

15. Nayak, S. \& Bahuguna, A. (2001) Application of remote sensing data to monitor mangroves and other coastal vegetation of India. Indian Journal of Marine Sciences, 30(4), 195-213.

16. Pitchaikani, S. J., Sarma, S. K., \& Bhattacharya, S. (2015) First time report on the weather patterns over the Sundarban mangrove forest, east coast of India. Indian Journal of GeoMarine Sciences, 1-11.

17. Rasul, G., \& Chaudhry, Z. Q. Review of Advance in Research on Asian Summer Monsoon. Pakistan Journal of Meteorology, 6 (12), 1-10.

18. Simple English Wikipedia. (2006) West Bengal. Available from: https:// simple. wikipedia.org/wiki/West_Bengal\#/media/File:West_Bengal_in_India_(disputed_hatched).sv g [Accessed $12^{\text {th }}$ August 2019]

19. USGS. Earth Explorer - Home. Available from https://earthexplorer.usgs.gov [Accessed $28^{\text {th }}$ August 2019]. 